\title{
The State of Europium Complexes on Alumina Surface
}

\author{
T. Yoshida, T. Tanaka, S. Yoshida, H. Handa*, S. Hikita*, T. Baba* and Y. Ono* \\ Department of Molecular Engineering, Kyoto University, Kyoto 606-01, Japan \\ * Department of Chemical Engineering, Tokyo Institute of Technology, Ookayama, Meguroku, Tokyo \\ 152, Japan
}

\begin{abstract}
Amide complexes of europium prepared by dissolving Eu in a liquid ammonia were fixed on alumina and heated at various temperatures in vacuo. The activity of the samples for the isomerization of 2,3-dimethylbut-1-ene changed remarkably with the evacuation temperature and the loading amount of Eu. XANES analysis of the samples showed that the Eu species are a mixture of divalent- and trivalent-ion complexes and the samples exhibiting high activity include only divalent Eu species. EXNFS analysis demonstrated that there are two kinds of divalent Eu species in the samples, $i$. e, the Eu species fixed by OH group on the alumina and the species consisting of Eu ions bridged by nitrogen. EXAFS analysis also revealed that the former is the inactive Eu species, while the latter is the active species for isomerization of 2,3dimethylbut-1-ene. The catalytic activity closely related to the degree of the aggregation of the latter Euactive species.
\end{abstract}

\section{INTRODUCTION}

Amide complexes of europium prepared by dissolving $\mathrm{Eu}$ in a liquid ammonia were fixed on alumina (Eu/Al2 $\left.\mathrm{O}_{3}\right)$ and heated at various temperatures in vacuo. The activity of the samples for the isomerization of 2,3-dimethylbut-1-ene to 2,3-dimethylbut2-cric was much influenced by the loading amount of Eu. The Eu/Al $2 \mathrm{O}_{3}$ loading Eu less than 5 wi\% was inactive, while above $5 \mathrm{wt} \%$, the catalytic activity increased with the Eu loading until $8 \mathrm{wt} \%$ and then the activity fell off. In addition, the catalytic activity changed remarkably with the evacuation temperature, and it reached a maximum when the sample was evacuated at around $480 \mathrm{~K}$. These results suggest that the valence and the structure of Eu species are different by the loading amount of Eu and the evacuation temperature. In the present work, XANES and EXAFS have been applied to clarify the electronic state and the local structure of Eu species supported on alumina.

\section{EXPERIMENTAL}

$\mathrm{Eu} / \mathrm{Al}_{2} \mathrm{O}_{3}$ were prepared by an impregnation method.[1] The $\mathrm{Al}_{2} \mathrm{O}_{3}$ was impregnated with an Eu metal solution of liquid ammonia under an inert condition, followed by evacuation at various temperatures for $1 \mathrm{~h}$. The Eu/ $\mathrm{Al}_{2} \mathrm{O}_{3}$ evacuated at $\mathrm{T}$ (T: $353-973 \mathrm{~K}$ ) are referred to as $\mathrm{Eu} / \mathrm{Al}_{2} \mathrm{O}_{3}(\mathrm{~T})$ hereinafter.

X-ray absorption (XA) experiments were carried out at beam line $7 \mathrm{C}$ station at Photon Factory in National Laboratory for High Energy Physics (KEK-PF) with a ring energy, $2.5 \mathrm{GeV}$ and stored current, 250 - $350 \mathrm{~mA}$ (Proposal no. 91-175 and 93G168). XA data of $\mathrm{Eu} / \mathrm{Al}_{2} \mathrm{O}_{3}$ were collected in a fluorescence mode at room temperature with an $\mathrm{Si}(111)$ two-crystal monochromator. Each XA spectrum of an $\mathrm{Eu} / \mathrm{Al}_{2} \mathrm{O}_{3}$ was recorded using an in situ cell made of Pyrex glass with a Kapton window. The non-linear curve-fitting analysis was performed for the Fourier-filtered EXAFS by using empirical parameters extracted from EXAFS of reference compounds and those compiled in FEFF package.[2] The parameters for Eu-O or Eu-N (Eu-O,N) were extracted from the EXAFS of cubic C-type $\mathrm{Eu}_{2} \mathrm{O}_{3}$. For the Eu-Eu shells, we used those compiled in FEFF package. For Eu-Al shell, we adopted the phase shift for an Eu-Mg shell obtained by calculating from those of Eu-O, Ni-O and $\mathrm{Ni}-\mathrm{Mg}$ shells. The phase shifts for $\mathrm{Ni}-\mathrm{O}$ and $\mathrm{Ni}-\mathrm{Mg}$ shells were extracted from the EXAFS of a $\mathrm{NiO}$ and $\mathrm{Ni} 0.02 \mathrm{Mg} 0.98 \mathrm{O}$ solid solution, [3] respectively. For the backscattering amplitude of $\mathrm{Al}$, we also adopted the parameter for $\mathrm{Ni}-\mathrm{Mg}$ shell.

\section{RESULTS AND DISCUSSION}

Fig. 1 shows Eu L3-edge XANES spectra of $8 \mathrm{wt} \%$ and $4 \mathrm{wt} \% \mathrm{Eu} / \mathrm{Al}_{2} \mathrm{O}_{3}$ evacuated at various temperatures. The spectra exhibit two absorption maxima at 6972 and $6980 \mathrm{eV}$, so-called white lines, indicating that Eu/Al2 $\mathrm{O}_{3}$ samples consist of at least two kinds of Eu species. From the peak positions, these peaks are assignable to $2 \mathrm{p} 3 / 2-5 \mathrm{~d}$ transition in $\mathrm{Eu}^{2+}$ and Eu${ }^{3+}$ ions, respectively.[4] To estimate the fraction of $\mathrm{Ev}^{2+}$. and $\mathrm{Eu}^{3+}$ species, we carried out deconvolution[5, 6] of each XANES spectrum with two sets of a Lorentzian for a white line and an arctangent function for a continuum absorption. In the present case, the sums of the areas of two white lines were found to be constant for all samples (ca. $16.5 \mathrm{eV}$ unit), suggesting that the ratio of areas indicates directly the ratio of $\mathrm{Eu}^{2+}$ and $\mathrm{Eu}^{3+}$ species. The fraction of $\mathrm{Eu}^{2+}$ species closed to $100 \%$ in 
$\mathrm{Eu} / \mathrm{Al}_{2} \mathrm{O}_{3}$ samples evacuated around $500 \mathrm{~K}$, which samples exhibited high activity for the isomerization reaction. This result clearly indicates that $\mathrm{Eu}^{2+}$ species is the active species for the isomerization of 2,3-dimethylbut-1-ene. However, the change of the catalytic activity did not correlate to the valence variation of Eu species. For example, the fractions of Eu ${ }^{2+}$ species in $\mathrm{Eu} / \mathrm{Al}_{2} \mathrm{O}_{3}$ samples evacuated at $473 \mathrm{~K}$ and $573 \mathrm{~K}$ are almost the same ( $93 \%$ and $85 \%$, respectively), but the catalytic activity of $\mathrm{Eu} / \mathrm{Al}_{2} \mathrm{O}_{3}(473 \mathrm{~K})$ is much higher by a factor of ten than that of $\mathrm{Eu} / \mathrm{Al}_{2} \mathrm{O}_{3}(573 \mathrm{~K})$. In addition, the dominant valence state of $\mathrm{Eu}$ is divalent in $4 \mathrm{wt} \% \mathrm{Ev} / \mathrm{Al}_{2} \mathrm{O}_{3}(423 \mathrm{~K})$, but the activity of this sample was inactive for the reaction.

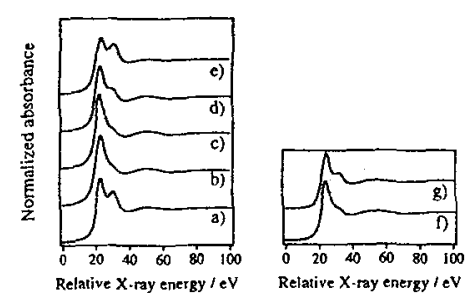

Figure 1: Ea L3-edge normalized XANES spectra of 8 wt $\% \mathrm{Eu} / \mathrm{Al} 2 \mathrm{O}_{3}$ evacuated at a) 353 , b) 423 , c) 473 , d) 573 and e) $973 \mathrm{~K}$ and those of $4 \mathrm{wt} \% \mathrm{Eu}_{/} / \mathrm{Al}_{2} \mathrm{O}_{3}$ evacuated at $\mathrm{f}$ ) 423 and g) $523 \mathrm{~K}$. Energy offset is taken to be $6950.0 \mathrm{eV}$.
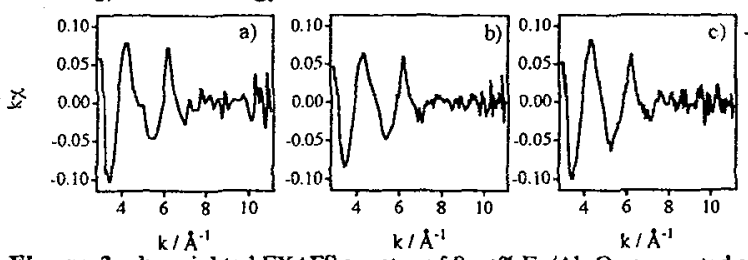

\section{$\mathrm{N}$}

a) Relative Debye-Waller factors against those of reference samples. b) Debye-Wallex factors. The estimated errors in $N$ and $R$ are $\pm 10 \%$ and $\pm 0.02 \AA$, respectively.

Figure 2: $\mathrm{k}$-weighted EXAFS spectra of $8 \mathrm{wt} \% \mathrm{Ez} / \mathrm{Al}_{2} \mathrm{O}_{3}$ evacuated at a) $473 \mathrm{~K}$

and b) $573 \mathrm{~K}$ and that of c) $4 \mathrm{wt} \% \mathrm{Eu} / \mathrm{Al}_{2} \mathrm{O}_{3}$ evacuated at $423 \mathrm{~K}$.

Fig. 2 shows $k$-weighted Eu L 3 -edge EXAFS spectra of $8 \mathrm{wt} \% \mathrm{Ev} / \mathrm{Al}_{2} \mathrm{O}_{3}\left(473\right.$ and $573 \mathrm{~K}$ ) and $4 \mathrm{wt} \% \mathrm{Eu} / \mathrm{Al}_{2} \mathrm{O}_{3}(423 \mathrm{~K})$. As for all Eu/Al $\mathrm{O}_{3}$ samples, EXAFS spectra show fundamentally the same patterns. However, the shoulder around $5 \AA^{-1}$ seen in the EXAFS of 8 wi\% Eu/ $/ \mathrm{Al}_{2} \mathrm{O}_{3}(473 \mathrm{~K})$ can not be observed in the EXAFS spectrum of $4 \mathrm{wt} \% \mathrm{Eu} / \mathrm{Al}_{2} \mathrm{O}_{3}(423 \mathrm{~K})$. We also carried out curve-fitting analysis against the Fourier-filtered EXAFS spectra of these samples. The results are summarized in Table 1. It is revealed that there are short and long Eu-O or Eu-N bonds in all the samples. On the other hand, the curvefitting analysis also shows that both neighboring $\mathrm{Eu}$ and $\mathrm{Al}$ atoms exist in $8 \mathrm{wt} \% \mathrm{Eu} / \mathrm{Al}_{2} \mathrm{O}_{3}$ samples, whereas only neighboring $\mathrm{Al}$ atom exists in $4 \mathrm{w} \% \mathrm{Eu} / \mathrm{Al}_{2} \mathrm{O}_{3}$ sample. One of the two kinds of Eu-O,N bonds is assigned to the nitrogen atoms of amide or imide groups bonded to Eu atoms on the basis of the results of IR measurements. [1, 7] The other Eu-O,N bond and the neighboring $\mathrm{AI}$ atom would indicate the formation of $\mathrm{Eu}-\mathrm{O}-\mathrm{Al}$ bond, because IR study showed that Eu atoms react with $\mathrm{OH}$ groups on the alumina surface.[8] As for the neighboring Eu atom, the curve-fitting analysis indicates that the number of the Eu atom in $8 \mathrm{wt} \% \mathrm{Eu} / \mathrm{Al}_{2} \mathrm{O}_{3}$ decreases from 1.5 to 0.7 as the evacuation temperature rises from $473 \mathrm{~K}$ to 573 $\mathrm{K}$. In the temperature region of $473-573 \mathrm{~K}$, we detected the desorption of $\mathrm{NH}_{3}$ gas from the Eu/Al2 $\mathrm{O}_{3}$ sample by the TPD measurement. [8] Therefore, the neighboring Eu atom is assignable to the Eu atoms bridged by nitrogen atoms. The decrease of the coordination number of Eu-Eu shell in $8 \mathrm{wt} \% \mathrm{Eu} / \mathrm{Al}_{2} \mathrm{O}_{3}(573 \mathrm{~K})$ probably results from the desorption of the bridging nitrogen atoms as $\mathrm{NH}_{3}$. These curve-fitting results strongly demonstrate that divalent Eu ions preferentially react with $\mathrm{OH}$ group on $\mathrm{Al}_{2} \mathrm{O}_{3}$ surface to form the isolated Eu species in $4 \mathrm{wt} \% \mathrm{Eu} / \mathrm{Al}_{2} \mathrm{O}_{3}$ while the additional Eu species consisting of the $\mathrm{Eu}$ atoms bridged by the nitrogen atom are formed in $8 \mathrm{wt} \% \mathrm{Eu} / \mathrm{Al}_{2} \mathrm{O}_{3}$. Therefore, we conclude that the former Eu species is inactive for the isomerization of 2,3-dimethylbut-1-ene, but the latter Eu species is active, by comparison with the catalytic activity of $4 \mathrm{wt} \% \mathrm{Eu} / \mathrm{Al}_{2} \mathrm{O}_{3}(423 \mathrm{~K})$ and $8 \mathrm{wt} \% \mathrm{Eu} / \mathrm{Al}_{2} \mathrm{O}_{3}(473$ and $573 \mathrm{~K})$. In addition, the coordination number of the neighboring $\mathrm{Eu}$ atom in $8 \mathrm{w} \% \mathrm{Eu} / \mathrm{Al}_{2} \mathrm{O}_{3}(473 \mathrm{~K})$ would indicate that the highest activity for the isomerization of $2,3-$ dimethylbut-1-ene is obtained when Eu dimer or trimer is formed. One of the important factors controlling the catalytic activity of Eu/ $\mathrm{Al}_{2} \mathrm{O}_{3}$ should be the degree of the aggregation of the active Eu species.

\section{References}

[1] T. Baba, G. J. Kim and Y. Ono, J. Chem. Soc. Faraday Trans., 88 (1992) 891-897.

[2] J. J. Rehr, S. I. Zabinsky and R. C. Albers, J. Am. Chem. Soc., 113 (1991) 5135-5140.

[3] T. Yoshida, T. Tanaka, H. Yoshida, T. Funabiki and S. Yoshida, J. Phys. Chem., 100 (1996) 2302-2309.

[4] J. Röher, Physica B, 144 (1986) 27-31.

[5] T. Tanaka, T. Hanada, S. Yoshida, T. Baba and Y. Ono, Jpn. J. Appl. Phys, 32 (1993) 481-483.

[6] T. Tanaka, T. Yoshida, S. Yoshida, T. Baba and Y. Ono, Physica B, $208 \& 209$ (1995) 687-688.

[7] T. Baba, S. Hikita, Y. Ono, T. Yoshida, T. Tanaka and S. Yoshida, J. Mol. Catal., 98 (1995) 49-55.

[8] Preparation for publication. 